\title{
Unjuk Kerja Mesin Diesel Berbahan Bakar Campuran Biodiesel Jarak dan Biodiesel Jelantah
}

\author{
(The Performance of Diesel Engine using Mixed of Jatopra Biodiesel and Waste Cooking Oil \\ Biodiesel) \\ Wahyudi $^{a}$, Sarip ${ }^{b}$, Sudarja $^{c}$, Haris Suhatno ${ }^{d}$ \\ ${ }^{a, c}$ Program Studi Teknik Mesin, Fakultas Teknik, Universitas Muhammadiyah Yogyakarta \\ Jl, Brawijaya, Kasihan, Bantul, Yogyakarta - 55183. \\ e-mail:wahyudi@ft.umy.ac.id, sudarja_msn@yahoo.com \\ ${ }^{b, d}$ Program Studi Teknik Mesin, Sekolah Tinggi Teknologi Ronggolawe Cepu, \\ JI Kampus Ronggolawe Blog B No.1. Mentul, Blora, Jawa Tengah 58315 \\ e-mail: hidayatullohsarip566@gmail.com
}

\begin{abstract}
Abstrak
Cadangan bahan bakar fosil yang bersifat tidak dapat diperbarui semakin menipis. Pengembangan energi terbarukan perlu dilakukan untuk mengurangi ketergantungan terhadap bahan bakar fosil, diantaranya dengan pemanfaatan minyak nabati menjadi biodisel. Pada penelitian ini digunakan bahan baku biodisel campuran minyak jarak dan biodisel minyak jelantah yang dikombinasikan dengan minyak solar. Tujuan penelitian ini adalah untuk mengetahui kinerja dari mesin disel dengan menggunakan bahan bakar solar $100 \%$ dan campuran biodisel jarak - jelantah dan solar dengan variasi $5 \%$ biodisel - 95\% solar (B5), 10\% biodisel - 90\% solar (B10) dan 15\% biodisel $85 \%$ solar (B15). Penelitian dimulai dengan melakukan pengujian sifat fisis bahan bakar meliputi viskositas, densitas, flashpoint, nilai kalor. Selanjutnya dilakukan uji unjuk kerja mesin disel. Hasil penelitian menunjukkan bahwa daya yang dihasilkan dari bahan bakar B5, B10, B15 masih lebih rendah daripada bahan bakar solar murni. Laju konsumsi bahan bakar pada biodisel B5, B10, dan B15 lebih rendah dibanding bahan bakar solar murni.
\end{abstract}

Kata kunci: Biodisel jarak, biodisel jelantah, unjuk kerja mesin disel

\begin{abstract}
Reserves of non-renewable fossil fuels are diminishing. Renewable energy development needs to be done to reduce dependence on fossil fuels, including the utilization of vegetable oil into biodiesel. This research used a mixture of jatropha and waste cooking oil biodiesel combined with diesel oil. The purpose of this study was to determine the performance of diesel engines using $100 \%$ diesel fuel and biodiesel with a variation of $5 \%$ biodiesel - 95\% diesel (B5), 10\% biodiesel - 90\% diesel (B10) and 15\% biodiesel - 85\% diesel (B15). The study has begun by testing the physical properties of the fuel, including viscosity, density, flashpoint, heating value. Then the diesel engine performance test was carried out. The results showed that the power produced from B5, B10, B15 fuels was lower than pure diesel fuel. The fuel consumption rate of B5, B10, and B15 biodiesel is lower than pure diesel fuel.
\end{abstract}

Keywords: Jatropha biodiesel, waste cooking biodiesel, diesel engine performance

\section{Pendahuluan}

Sampai saat ini, minyak bumi yang merupakan energi tak terbarukan masih menjadi salah satu sumber utama energi, sedangkan ketersediaannya semakin terbatas. Sebagai bahan bakar tak terbarukan, minyak bumi akan semakin menipis dan mungkin habis [1]. Sementara kebutuhan energi semakin meningkat. Untuk itu, diperlukan adanya sumber energi pengganti minyak bumi. 
Salah satu bahan bakar pengganti yang sangat potensial untuk dikembangkan adalah biodisel. Biodisel berasal dari minyak nabati ataupun minyak hewani yang diproses melalui reaksi transesterifikasi dan dapat digunakan sebagai bahan bakar disel [2]. Minyak nabati lebih banyak digunakan karena ketersediaan bahan baku yang melimpah. Bahan baku yang dapat digunakan untuk pembuatan biodisel antara lain tanaman jarak, minyak jelantah, kelapa sawit, biji nyamplung, kemiri, karet dan jenis tumbuhan lainnya [2].

Indonesia memiliki potensi besar untuk mengembangkan biodisel, karena bahan baku biodisel yang sangat mudah ditemukan di Indonesia, seperti tanaman jarak pagar (Jatropha curcas) [3]. Di sisi lain, diperlukan pengelolaan limbah minyak goreng bekas atau yang lebih dikenal minyak jelantah (waste cooking oi). Minyak jelantah merupakan limbah yang jika tidak dikelola dengan baik, akan menimbulkan gangguan pada lingkungan [4].

Sifat fisika dan kimia biodisel minyak jelantah yang diproses dengan cara transesterifikasi mendekati sifat minyak disel [5]. Minyak nabati mempunyai nilai kalor mendekati dengan bahan bakar konvensional, akan tetapi penggunaan secara langsung sebagai bahan bakar masih memiliki kendala karena nilai viskositasnya yang relatif tinggi. Tingginya viskositas tersebut dapat mengakibatkan pembakaran kurang sempurna dan dapat menghambat kinerja dari injection pump sehingga injector pump akan mudah mengalami kerusakan [6].

Salah satu upaya untuk menurunkan viskositas adalah melalui proses transesterifikasi. Proses transesterifikasi merupakan cara yang paling banyak dilakukan karena tidak membutuhkan energi dan suhu yang tinggi. Reaksi ini akan menghasilkan metil atau etil ester, tergantung dari jenis alkohol yang direaksikan. Biodisel campuran minyak jarak dan minyak jelantah memberikan sifat fisis yang semakin baik dibandingkan biodisel jarak atau biodisel jelantah murni [7]. Namun, penggunaannya pada mesin disel belum bisa dilakukan tanpa campuran solar karena viskositasnya belum memenuhi standar. Penelitian ini bertujuan mengetahui unjuk kerja mesin disel dengan bahan bakar biodisel campuran jarak dan jelantah dengan persentase biodisel 5\% (B5), 10\% (B10) dan 15\% (B15).

\section{MetOde}

\subsection{Bahan}

Bahan-bahan yang digunakan pada penelitian ini yaitu minyak jarak, minyak jelantah dan minyak solar. Sifat fisik minyak nabati tersebut disajikan pada Tabel 2.1 berikut.

Tabel 2.1. Sifat fisik minyak nabati

\begin{tabular}{ccccc}
\hline Bahan baku & $\begin{array}{c}\text { Densitas } \\
\left(\mathbf{k g} / \mathbf{m}^{\mathbf{3}}\right)\end{array}$ & $\begin{array}{c}\text { Viskositas } \\
(\mathbf{c S t})\end{array}$ & $\begin{array}{c}\text { Titik } \\
\text { Nyala }{ }^{\circ} \mathbf{C}\end{array}$ & $\begin{array}{c}\text { Nilai kalor } \\
(\mathbf{c a l} / \mathbf{g})\end{array}$ \\
\hline Minyak Jarak & 937 & 193,55 & 309,7 & $8.889,78$ \\
Minyak Jelantah & 893 & 56,16 & 305,3 & $9.224,87$ \\
\hline
\end{tabular}

\subsection{Langkah Penelitian}

\subsubsection{Pembuatan biodisel dan campurannya.}

Masing-masing minyak nabati murni ditransesterifikasi menjadi biodisel. Proses transesterifikasi dilakukan menggunakan Metanol (15\% dari volume minyak) dan Kalium Hidroksida $(\mathrm{KOH})$ sebagai katalis. Bahan-bahan tersebut diaduk selama 60 menit pada temperatur $60^{\circ} \mathrm{C}$. Setelah proses pemisahan biodisel dari gliserol, pada tahap akhir dilakukan pencucian dan pengeringan pada biodisel. Selanjutnya dibuat campuran biodisel jarak dan biodisel minyak jelantah dengan perbandingan 40\%: $60 \%$. Campuran biodisel dengan minyak solar dilakukan dengan variasi biodisel $5 \%$ berbanding solar $95 \%$, biodisel $10 \%$ berbanding solar $90 \%$, dan biodisel $15 \%$ berbanding solar $85 \%$.

\subsubsection{Pengujian karakteristik bahan bakar}

Pengujian ini dilakukan untuk mengetahui sifat biodisel dan campurannya. Sifat yang diteliti meliputi densitas, viskositas, titik nyala dan nilai kalor. Densitas dan viskositas diukur 
pada temperature $40{ }^{\circ} \mathrm{C}$. Pengujian titik nyala dilakukan menggunakan cleveland open cup. Data nilai kalor bahan bakar duiji menggunakan kalorimeter bom.

\subsubsection{Pengujian unjuk kerja mesin diesel}

Pengujian ini dilakukan untuk mengetahui perbedaan besar daya yang dihasilkan masing-masing bahan bakar pada mesin disel. Pengujian ini menggunakan mesin disel merk Jiangdong satu silinder. Bahan bakar yang digunakan adalah solar murni dan campurannya dengan biodisel jarak - jelantah pada variasi B5, B10, dan B15. Proses pengujian unjuk kerja mesin dilakukan pada putaran stasioner, yaitu pada posisi $2600 \mathrm{rpm}$ atau pada throttle terbuka penuh. Kemudian dilakukan pembebanan terhadap mesin disel menggunakan satu lampu hingga lima lampu dengan daya masing-masing lampu 500 watt dan dinyalakan secara berurutan. Untuk mengetahui daya listrik yang dihasilkan, dilakukan pengukuran arus menggunakan ampere meter dan pengukuran tegangan menggunakan voltmeter. Langkah ini diulangi untuk seluruh variasi perbandingan bahan bakar.

\subsubsection{Pengujian laju konsumsi bahan bakar}

Pengujian ini dilakukan untuk mengetahui perbedaan besar konsumsi masing masing bahan bakar pada mesin diesel. Pengukuran konsumsi bahan bakar dilakukan menggunakan burret. Bahan bakar yang diuji adalah solar murni dan campurannya dengan biodisel jarak - jelantah pada variasi B5, B10, dan B15.

Skema alat uji unjuk kerja mesin disel disampaikan pada gambar 2.1 berikut.

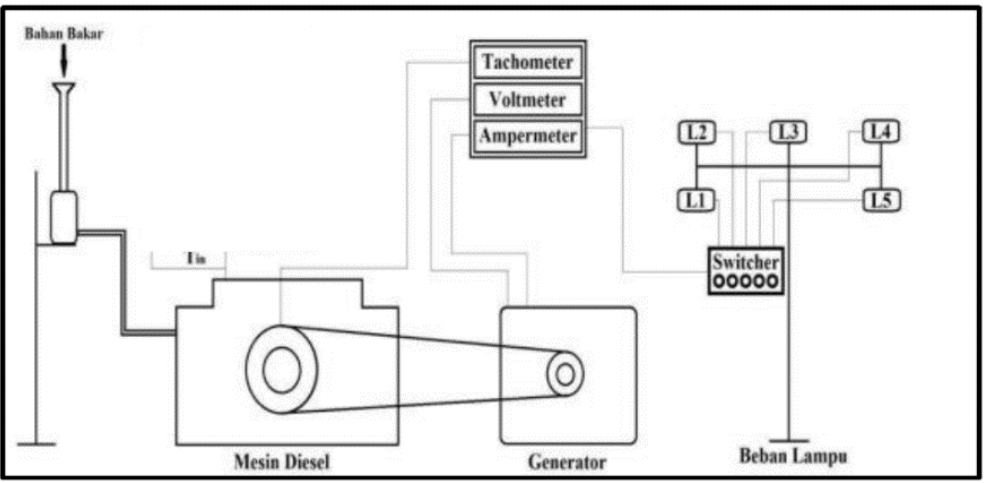

Gambar 2.1. Skema alat uji unjuk kerja mesin diesel.

\section{Hasil dan Pembahasan}

\subsection{Sifat Fisik Bahan Bakar}

Syarat mutu biodisel untuk viskositas adalah antara $2 \mathrm{cSt}$ sampai $4,5 \mathrm{cSt}$, untuk densitas adalah antara $815 \mathrm{~kg} / \mathrm{m}^{3}$ sampai $860 \mathrm{~kg} / \mathrm{m}^{3}$, sedangkan titik nyala minimal adalah $100^{\circ} \mathrm{C}[8]$.

Sifat fisik campuran biodiesel jarak - jelantah dengan solar variasi B5, B10, dan B15 dapat dilihat pada tabel 3.1.

Tabel 3.1. Perbandingan sifat fisik biodiesel variasi B5, B10, B15 dan solar

\begin{tabular}{lccrr}
\hline Bahan bakar & $\begin{array}{c}\text { Densitas } \\
\left(\mathbf{k g} / \mathbf{m}^{\mathbf{3}}\right)\end{array}$ & $\begin{array}{c}\text { Viskositas } \\
(\mathbf{c S t})\end{array}$ & $\begin{array}{c}\text { Titik } \\
\text { Nyala }\end{array}$ & \multicolumn{1}{c}{$\begin{array}{c}\text { Nilai } \mathbf{~ k a l o r} \\
(\mathbf{c a l} / \mathbf{g})\end{array}$} \\
\hline Solar Industri & 826 & 3,63 & 60,7 & $10.970,03$ \\
B5 & 784 & 3,78 & 87,4 & $10.669,84$ \\
B10 & 786 & 4,07 & 92,9 & $10.810,52$ \\
B15 & 911 & 4,17 & 93,6 & $10.655,63$ \\
Biodiesel Jarak Jelantah & 850 & 6,53 & 184,5 & $8.958,99$ \\
\hline
\end{tabular}


Dari Tabel 3.1, terlihat bahwa biodisel yang telah dicampur dengan minyak solar memiliki nilai sifat fisik yang mendekati nilai sifat fisik minyak solar. Nilai viskositas dari suatu bahan bakar merupakan sifat penting dari bahan bakar. Viskositas berpengaruh pada kemampuan atomisasi bahan bakar tersebut [9]. Viskositas campuran biodisel semakin tinggi dengan bertambahnya persentase biodisel.

Besar kecilnya massa bahan bakar yang diijeksikan ke ruang bakar tergantung dari nilai densitas bahan bakar tersebut. Densitas campuran biodisel jarak-jelantah lebih tinggi dari minyak solar. Titik nyala biodisel jarak-jelantah jauh berkurang setelah dicampur dengan minyak solar. Namun, titik nyala B5, B10 dan B15 lebih tinggi dari flash point minyak solar, sehingga lebih aman proses penyimpanannya. Nilai kalor biodiesel lebih kecil daripada nilai kalor minyak solar. Semakin banyak persentase biodisel pada bahan bakar, nilai kalor bahan bakar tersebut semakin berkurang. Nilai kalor campuran biodisel tidak terpaut jauh dengan nilai kalor minyak solar.

\subsection{Pengaruh Persentase Biodisel terhadap Laju Konsumsi Bahan Bakar}

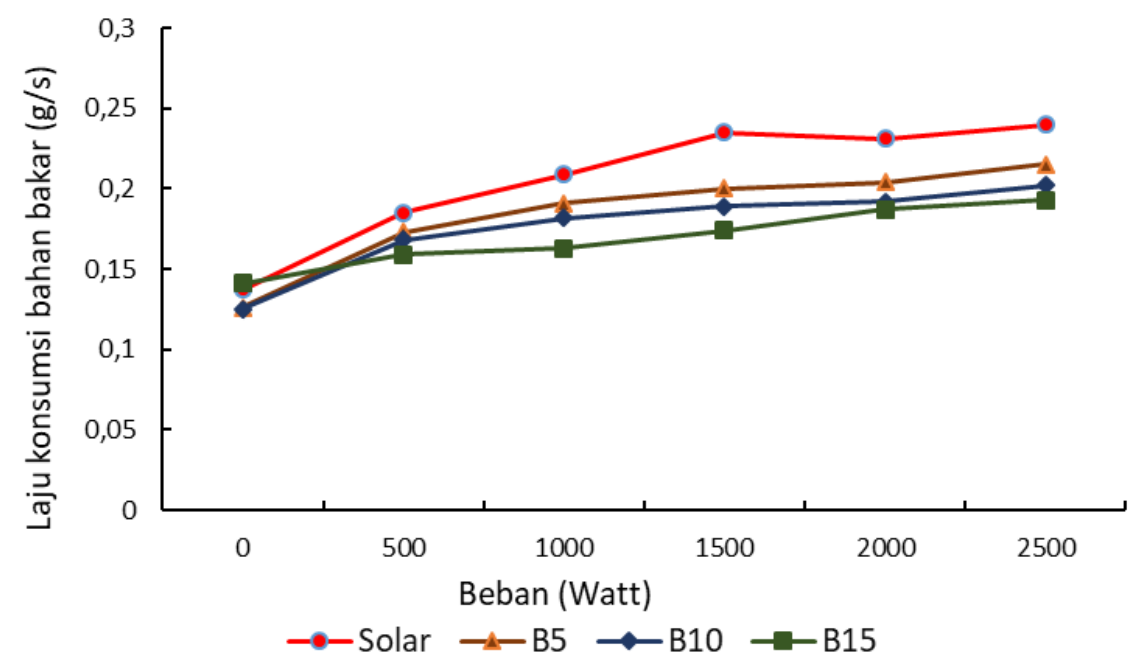

Gambar 3.1. Grafik laju konsumsi bahan bakar terhadap beban mesin diesel dengan bahan bakar solar dan biodiesel variasi B5, B10, B15.

Laju konsumsi bahan bakar menunjukkan besarnya massa bahan bakar yang dikonsumsi mesin tiap satuan waktu. Gambar 3.1 menunjukkan grafik laju konsumsi bahan bakar terhadap beban mesin disel. Bahan bakar dengan persentase biodisel yang lebih tinggi memiliki laju konsumsi bahan bakar yang lebih rendah. Selisih nilai laju konsumsi bahan bakar antara bahan bakar B5, B10, B15 dengan minyak solar berkisar antara 6,5\% sampai $26 \%$.

Viskositas dan densitas berpengaruh terhadap laju konsumsi bahan bakar. Bahan bakar dengan viskositas yang tinggi mengakibatkan bahan bakar sulit dialirkan maupun diinjeksikan [10]. Semakin tinggi kandungan biodisel pada campuran bahan bakar, viskositas bahan bakar tersebut semakin tinggi. Densitas yang tinggi memberikan massa per volume yang lebih banyak [11]. Biodisel memiliki densitas yang lebih tinggi dari minyak solar, sehingga massa bahan bakar yang diinjeksikan akan lebih banyak.

\subsection{Pengaruh Persentase Biodisel terhadap Putaran Mesin Diesel}

Pengaruh persentase biodisel terhadap putaran mesin ditunjukkan pada Gambar 3.2 Semakin besar beban yang diberikan maka putaran mesin semakin menurun. Bahan bakar solar murni menghasilkan putaran mesin paling tinggi dibandingkan dengan bahan bakar biosolar variasi B5, B10 maupun B15, sedangkan variasi bahan bakar biosolar B15 memiliki putaran mesin terendah dari semua jenis variasi bahan bakar. Selisih putaran mesin yang dihasilkan oleh biodisel terhadap minyak solar tidak lebih dari 0,55\%. Putaran mesin sebanding dengan laju konsumsi bahan bakar (Gambar 3.1 dan Gambar 3.2). Berdasarkan 
hal tersebut, sifat fisik bahan bakar terutama viskositas dan densitas berpengaruh pada putaran mesin.

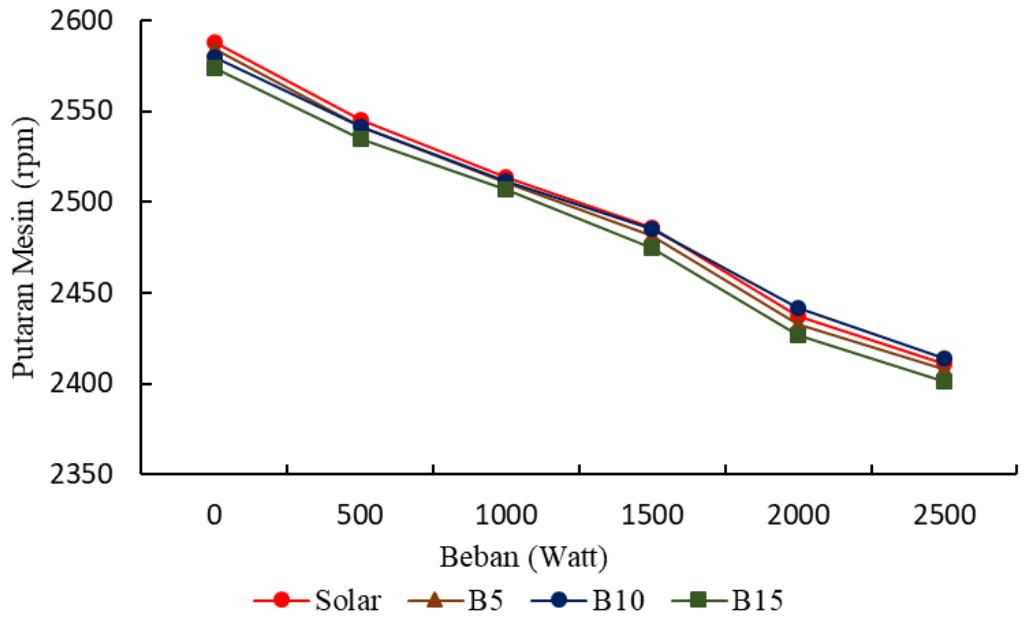

Gambar 3.2. Grafik putaran mesin terhadap beban pada mesin diesel dengan bahan bakar solar dan biodiesel B5, B10, B15.

\subsection{Pengaruh Persentase Biodiesel terhadap Daya Listrik}

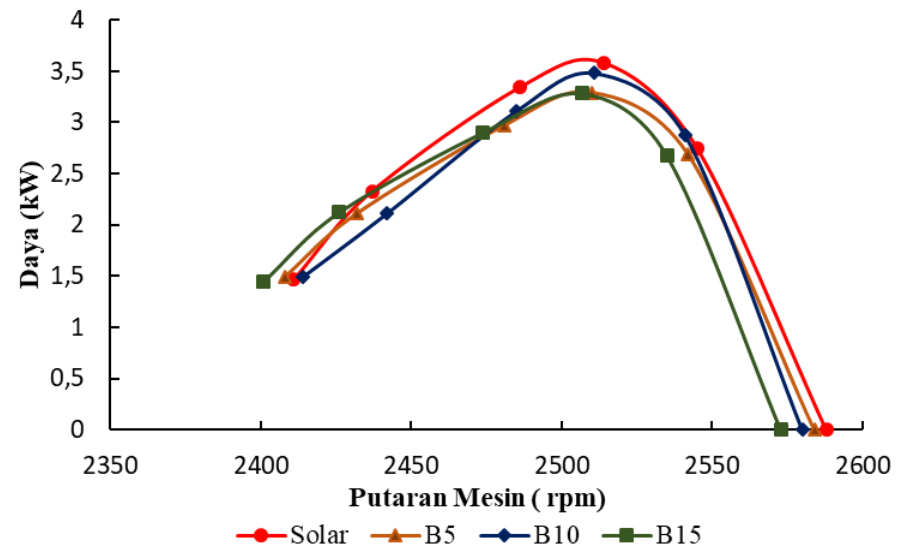

Gambar 3.3.. Grafik daya output terhadap putaran mesin diesel dengan bahan bakar solar dan biodiesel variasi $B 5, B 10, B 15$

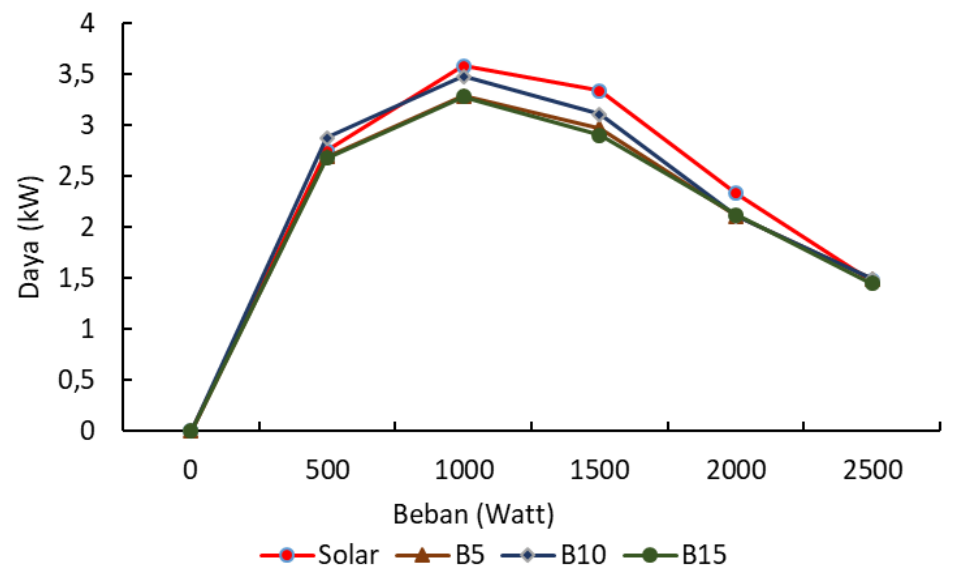


Gambar 3.4. Grafik daya output terhadap beban mesin diesel dengan bahan bakar solar dan biodiesel variasi $B 5, B 10, B 15$

Gambar 3.3 menunjukkan grafik daya terhadap putaran mesin, sedangkan Gambar 3.4 menunjukkan grafik daya terhadap beban. Bahan bakar solar menghasilkan daya yang paling tinggi dibanding bahan bakar lainnya. Perbedaan daya yang dihasilkan oleh masingmasing bahan bakar dipengaruhi oleh nilai sifat fisiknya terutama nilai kalor masing-masing bahan bakar. Bahan bakar dengan nilai kalor yang tinggi berarti memiliki kandungan energi yang tinggi pula, sehingga akan menghasilkan daya output yang tinggi. Biodisel memiliki nilai kalor lebih rendah daripada minyak solar. Semakin tinggi kandungan biodisel pada bahan bakar, daya yang dihasilkan mesin disel semakin turun.

\section{KESIMPULAN}

Berdasarkan hasil dan pembahasan di atas, dapat disimpulkan bahwa campuran biodisel jarak-jelantah dengan minyak solar sampai dengan B15 memiliki sifat fisis mendekati minyak solar. Viskositas, titik nyala, dan nilai kalor bahan bakar biosolar B5, B10 dan B15 berada di antara sifat biodisel jarak-jelantah dan minyak solar. Sifat fisis campuran biodisel berpengaruh pada laju konsumsi bahan bakar. Campuran biodisel memiliki laju konsumsi bahan bakar yang lebih rendah dari minyak solar. Sifat fisis campuran biodisel juga berpengaruh pada putaran mesin dan daya yang dihasilkan. Campuran biodisel menghasilkan putaran mesin dan daya sedikit lebih rendah dari minyak solar.

\section{Daftar Pustaka}

[1] A. E. Atabani et al., "A comparative evaluation of physical and chemical properties of biodiesel synthesized from edible and non-edible oils and study on the effect of biodiesel blending," Energy, vol. 58, pp. 296-304, Sep. 2013, doi: 10.1016/j.energy.2013.05.040.

[2] A. S. Silitonga, H. H. Masjuki, T. M. I. Mahlia, H. C. Ong, W. T. Chong, and M. H. Boosroh, "Overview properties of biodiesel diesel blends from edible and non-edible feedstock," Renewable and Sustainable Energy Reviews, vol. 22, pp. 346-360, 2013.

[3] A. S. Silitonga, A. E. Atabani, T. M. I. Mahlia, H. H. Masjuki, I. A. Badruddin, and S. Mekhilef, "A review on prospect of Jatropha curcas for biodiesel in Indonesia," Renewable and Sustainable Energy Reviews, vol. 15, no. 8, pp. 3733-3756, 2011.

[4] A. Chhetri, K. Watts, and M. Islam, "Waste cooking oil as an alternate feedstock for biodiesel production," Energies, vol. 1, no. 1, pp. 3-18, 2008.

[5] K. A. Abed, "Effect of waste cooking-oil biodiesel on performance and exhaust emissions of a diesel engine," Egyptian Journal of Petroleum, p. 5, 2018.

[6] D. Agarwal and A. K. Agarwal, "Performance and emissions characteristics of Jatropha oil (preheated and blends) in a direct injection compression ignition engine," Applied thermal engineering, vol. 27, no. 13, pp. 2314-2323, 2007.

[7] W. Wahyudi, M. Nadjib, M. F. Bari, and F. W. Permana, "Increasing of quality biodiesel of Jatropha seed oil with biodiesel mixture of waste cooking oil," vol. 10, p. 7, 2019.

[8] Biodiesel SNI 7182_2015. Standar Nasional Indonesia. 2015.

[9] A. Demirbas, "Progress and recent trends in biodiesel fuels," Energy conversion and management, vol. 50, no. 1, pp. 14-34, 2009.

[10] C. A. W. Allen and K. C. Watts, "Comparative analysis of the atomization characteristics of fifteen biodiesel fuel types," Transactions of the ASAE, vol. 43, no. 2, p. 207, 2000.

[11] S. K. Hoekman, A. Broch, C. Robbins, E. Ceniceros, and M. Natarajan, "Review of biodiesel composition, properties, and specifications," Renewable and sustainable energy reviews, vol. 16, no. 1, pp. 143-169, 2012. 